\title{
In my remembered country: what poetry tells us about the changing perceptions of volcanoes between the nineteenth and twenty-first centuries
}

\author{
Arianna Soldati $^{1}$ and Sam Illingworth ${ }^{2}$ \\ ${ }^{1}$ Department of Earth and Environmental Sciences, Section for Mineralogy, Petrology and Geochemistry, \\ Ludwig-Maximilian-Universität München, Munich, Germany \\ ${ }^{2}$ Department of Natural Sciences, Manchester Metropolitan University, Manchester, UK
}

Correspondence: Arianna Soldati (arianna_soldati@hotmail.it)

Received: 21 August 2019 - Discussion started: 3 September 2019

Revised: 20 February 2020 - Accepted: 25 February 2020 - Published: 26 March 2020

Abstract. In this study we investigate what poetry written about volcanoes from the 1800 s to the present day reveals about the relationship between volcanoes and the societies and times represented by poets who wrote about them, including how it evolved over that time frame. In order to address this research question, we conducted a qualitative content analysis of a selection of 34 English-language poems written about human-volcano interactions. Firstly, we identified the overall connotation of each poem. Then, we recognised specific emerging themes and grouped them in categories. Additionally, we performed a quantitative analysis of the frequency with which each category occurs throughout the decades of the dataset. This analysis reveals that a spiritual element is often present in poetry about volcanoes, transcending both the creative and destructive power that they exert. Furthermore, the human-volcano relationship is especially centred around the sense of identity that volcanoes provide to humans, which may follow from both positive and negative events. These results highlight the suitability of poetry as a means to explore the human perception of geologic phenomena. Additionally, our findings may be relevant to the definition of culturally appropriate communication strategies with communities living near active volcanoes.

\section{Introduction}

We live on a geologically active planet, and volcanoes are one of the most visually impressive geological features of our world. Whereas most geologic phenomena (e.g. orogeny, erosion) occur slowly over a timescale of millions of years, being de facto invisible to us humans, volcanic activity is a fast process that can radically change the natural landscape within a matter of hours, directly affecting the nearby communities. There are 150 active volcanoes in the world, and at any given time, about 20 of them are erupting (Durant et al., 2010; Venzke, 2013). The range of volcanic activity is broad (effusive to explosive), and so is the spectrum of feelings they inspire (from awe to fear). Certainly, they do not leave us indifferent (see for example Esperanza et al., 2008)

The areal impact footprint of eruptions depends on their Volcano Explosivity Index (VEI). In the past, only large eruptions affecting people (i.e. occurring in inhabited areas) would have been reported and become known worldwide. Large eruptions (VEI $>4$ ) statistically occur every few years, and have footprints of tens of kilometres (Brown et al., 2015). Small eruptions $(\mathrm{VEI}<4)$ can also significantly affect the local population, but before the development of modern means of communication their occurrence would have frequently gone unreported beyond national boundaries. At the beginning of the nineteenth century there were 10 million people worldwide living within $100 \mathrm{~km}$ of volcanoes that have erupted during the Holocene (Siebert et al., 2011); nowadays, that number has increased to 800 million.

Volcanoes constitute a fundamental part of the Earth system, recycling elements from the mantle to the surface and the atmosphere. But cohabiting with them comes with a unique set of challenges and rewards for local communities. Understanding how people perceive volcanoes is fundamen- 
tal in shaping effective scientific communication strategies, including in times of crises (see for example Nave et al., 2016; Donovan et al., 2018; Avvisati et al., 2019). These perceptions may in turn be affected by a variety of factors, including scientific knowledge, spiritual beliefs, oral history, and personal experience (direct or indirect), which vary widely in space and time across different cultures and historical periods.

Monitoring people's perception of volcanoes is difficult. Psychologists sometimes work with local communities in the aftermath of eruptions (Paton et al., 2000; Sword-Daniels et al., 2018; Paton, 2019), yet these works mainly focus on a very small, specific part of the human-volcano interaction (i.e. the instances in which volcanic activity conflicts with human life) and therefore paint a partial, skewed view of this relationship. Additionally, these interventions have only become common practice in recent times, and therefore cannot shed light on the evolution of the relationship between humans and volcanoes over time.

A potential medium through which a more nuanced and expansive dataset of this relationship can be established is the arts. The arts might be thought of as ubiquitous expressions of human nature and have often been inspired by volcanoes, with notable examples including paintings by Turner (Daly, 2011), Warhol (Sigurdsson, 2015), and Munch (Olson et al., 2007). We can conceivably use art pieces to guide us in our understanding of how volcano-human relations have changed through time (Hamilton, 2013; Alexander, 2016) For example, previous research has shown how the colours of sunsets painted by famous artists can be used to estimate stratospheric particulate concentrations in the Earth's past atmosphere, revealing that ash and gas released during major volcanic eruptions enhanced sunlight scattering, making sunsets appear redder, as reflected by the paintings that were produced in the aftermaths of such events (Zerefos et al., 2014). Similarly, studies have been conducted which have dated volcanic eruptions through Neolithic cave paintings (Schmitt et al., 2014), investigated the extent to which artists have used volcanoes to represent societal upheaval and transformation (Sivard, 2011), and even demonstrated how drawing volcanoes can be used to empower children in informal learning environments (Weier, 2004). These examples concern mainly drawings and paintings, aside from which there has been a relative paucity in research that investigates how the arts might be used to shed light on changing perceptions of volcanoes, and how this information can be directly useful in the communication of volcanic hazards and risk in the modern era.

In this study, we begin to address this gap in the literature by choosing to focus on another form of art: poetry. While attempts to define what is and what is not poetry can be contentious (see for example Ribeiro, 2007), here we take poetry to be any written form that is composed by the line. We consider prose to be differentiated from poetry, in that prose is instead composed by sentences and is written with stan- dard grammatical structure. This line-by-line composition of poetry means that it is able to convey meaning in a concise manner, which in turn lends itself to analysis and interpretation. Poetry provides a powerful medium through which to interpret human behaviours and perceptions, and an analysis of poetry as data has been used to provide understanding on topics ranging from living with HIV (Poindexter, 2002) and dementia (Zeilig, 2014) to attitudes relating to environmental change (Illingworth and Jack, 2018) and compassion fatigue in nurses (Jack and Illingworth, 2017). In this study, we aim to build on this research, using poetry as a medium through which to investigate perceptions of human-volcano interactions. Whilst Donovan et al. (2011) and Skinner (2011) have also used poetry to gain insight into the human perception of a specific, erupting volcano (Montserrat), here we aim to conduct a wider study.

By conducting a detailed qualitative content analysis for a selection of volcano poetry, this study aims to understand how poets have interpreted the relationship between humans and volcanoes from the beginning of the nineteenth century to the modern day. In Sect. 2, we discuss the methodology that was utilised in this study, outlining why this approach was adopted and establishing its validity and reliability. Section 3 contains a discussion of how categories and themes emerged from our analysis, and how this relates to the research question defined in Sect. 2. Finally, Sect. 4 contains the conclusions of this study, along with directions for further research.

\section{Methodology}

The methodology that we have adopted in this study involved treating poetry as data, allowing for text to be analysed with respect to attitudes relating to volcanoes. While several other methods exist for the analysis of textual data (e.g. ethnography, phenomenology, grounded theory), we have chosen qualitative content analysis because of its ability to highlight both the context and the content of the chosen text, which for a subjective medium such as poetry is essential.

The methodology that is adopted in this study largely follows that of Illingworth (2020), insofar as the qualitative content analysis of the poetry is guided by these six steps: formulation of research questions, selection of poetry to be analysed, definition of codes and categories to be applied, outline and implementation of the coding process, determination of trustworthiness, and analysis of results. The first five of these steps are outlined below, with the analysis of the results presented in Sect. 3.

We note here that the poems that were analysed in this study are presented according to the following format: "poem name" by author name (year of publication). Links to the full texts of all these poems can be found in Soldati and Illingworth (2019). 


\subsection{Formulation of research question}

By performing a qualitative content analysis on poetry that has been written about volcanoes, but critically not for the purpose of research, this study aims to better understand the way in which poets, as representatives of the society and culture they live in, have interpreted the relationship between humans and volcanoes (both active and not). For the purposes of this study, this has been formulated into the following research question (RQ): what does poetry written about volcanoes reveal about the relationship between volcanoes and the societies and times represented by poets who wrote about them?

\subsection{Selection of poetry to be analysed}

We began by selecting poetry that mentioned or featured volcanoes in some capacity. In doing so we set ourselves three constraints. Firstly, the poetry must be written in English, or else have an author-sanctioned English translation; this constraint was because English is the only common language that is shared by the authors of this study. Secondly, the poems must have been written from 1800 onwards; this constraint was introduced to make the list more manageable for analysis purposes, and because this was when many consider volcanology to have first been fully established as a scientific discipline through the research of Ben Franklin, James Hutton, Alexander von Humboldt, and others (Sigurdsson, 2000). Finally, where possible, we aimed to find at least one poem per decade, in order to try and better capture any change in attitudes from the early nineteenth century to the present day. Given these constraints, we looked for poetry that mentioned the word "volcano" or "volcanoes" and which, in the first instance, came from recognised poets and/or well-established poetry journals, in the following three databases: Poetry Foundation, Poetry Society, and Poetry Archive. Additionally, we reached out to the volcanology research community through the volcanology listserv (volcano@lists.asu.edu) asking for further suggestions. Finally, we performed a manual Google search to fill in decade gaps.

At this stage, we had a list of 53 poems, spanning every decade from the 1800 s to the 2010 s. We then independently read these poems and filtered them according to two further criteria: only poems that were 100 lines or less were to be considered, and any poet could only have one of their poems considered for further analysis. The line limit was introduced in order to make the analysis more manageable, and a limit of one poem per poet was introduced to allow for a wider selection of voices to be considered, and also to improve the validity of the approach in terms of the triangulation of data (see Sect. 2.5). In instances where there were multiple poems from a single poet, we agreed upon the one that we both found to be the most aesthetically pleasing, prior to any formalised content analysis. Poems that were removed because
Table 1. Classification of the 41 poems according to their portrayal of the relationship between volcanoes and the societies and times represented by poets who wrote about them as either "positive", "negative", "positive and negative", "neutral" or "invalid". Here the rows represent who the coding was performed by (AS: Arianna Soldati; SI: Sam Illingworth; both: Arianna Soldati and Sam Illingworth).

\begin{tabular}{lrrrrr}
\hline Coder & Positive & Negative & $\begin{array}{r}\text { Positive and } \\
\text { negative }\end{array}$ & Neutral & Invalid \\
& & \multicolumn{3}{c}{} \\
\hline AS & 5 & 8 & 7 & 10 & 11 \\
SI & 13 & 16 & 0 & 9 & 3 \\
Both & 9 & 12 & 5 & 8 & 7 \\
\hline
\end{tabular}

of length included "The last days of Herculaneum" by Edwin Atherstone (which is over 500 lines long), while poets with more than one poem included Emily Dickinson (six poems, for whom "I have never seen "Volcanoes" was chosen) and Percy Bysshe Shelley (two poems, for whom "The Cloud" was chosen). Following the application of this further selection criteria, 41 poems remained available for analysis. Of those, seven were written by women. The higher representation of male poets is merely due to the higher number of male poets who wrote about volcanoes over the considered time span.

We then independently read each of the poems and categorised them as being either "positive", "negative", "positive and negative", "neutral", or "invalid" in their portrayal of volcanoes from a human perspective (in line with the RQ), the results of which can be seen in Table 1 .

Performing this analysis enabled each of us to better familiarise themselves with the poetry, and also highlighted any further poems that needed to be removed from the study, because they were invalid, i.e. those poems that did not concern the relationship between volcanoes and the societies and times represented by the poets who wrote about them. Following this individual analysis (the rows corresponding to AS and SI in Table 1), we met up to exchange their analyses and agree upon a broad classification of the poems in terms of connotation ("both" in Table 1). This broad categorisation was useful for three reasons. Firstly, it revealed several differences in how the poems had been individually categorised, highlighting how these differences could be discussed and developed, thereby helping to improve the trustworthiness of the subsequent in-depth content analysis by ensuring investigator triangulation (see Sect. 2.5). Secondly, it revealed that this broad categorisation of the connotations of the poems as positive, negative, positive and negative, or neutral was too broad to offer any in-depth analysis with respect to the RQ. Finally, this approach revealed additional poems that should be removed from the study because they did not obviously concern the relationship between volcanoes and the societies and times of the poets who wrote about them. For example, "Inside the Ghost Volcano" by Will Alexan- 
der (1998) was removed at this stage because the volcano was being used as an abstract metaphor from which no perspective of the perceived relationship between volcanoes and the societies and times of the poets who wrote about them could be directly observed. In total a further seven poems (the "invalid" column in Table 1) were removed following this step, resulting in a total of 34 poems on which we could perform a more in-depth content analysis. This further selection criteria meant that two decades were now absent from our study (1940 and 1960). However, given that every other decade from the 1800 s onwards was still present we were satisfied that we had a sufficient temporal representation of poems to conduct a detailed content analysis with respect to the RQ.

\subsection{Definition of codes and categories to be applied}

A conventional approach to qualitative content analysis was adopted in this study, with preconceived categories being avoided, and categories being determined by the implementation of the coding process instead (see Sect. 2.4). While in some instances a directed content analysis might be more appropriate, this methodology is usually used in those instances where an existing theory would benefit from further description (Hsieh and Shannon, 2005). As the research question to be addressed in this study is unique, a directed approach is inappropriate. Similarly, a summative content analysis (i.e. one in which the frequency of words and/or phrases was only quantitatively assessed) would fail to fully account for the context of the poetry alongside its content.

\subsection{Outline and implementation of the coding process}

Both of us individually read each of the 34 poems, and assigned codes to sections of the text (Table 2). As each new code emerged we individually went back through the poems that had previously been coded to check whether these also contained any lines that could be labelled with any newly emergent code. After coding all of the poetry in this manner, we independently read all of the poems in full again and made sure that each of them had been coded accurately and that a saturation of emergent codes had been reached, thereby improving the trustworthiness of the approach (see Sect. 2.5). As can be seen from Table 2, this resulted in a total of 28 codes ( 9 for SI and 19 for AS). We then read each of the poems again to make sure that no coding had been missed.

Following this independent coding process, the two individual code books (one for AS and one for SI) shown in Table 2 were combined in order to search for emergent categories. This categorisation of the individual codes was initially done by SI, before being modified by AS, and then ratified by both SI and AS, with both of us agreeing upon the five emergent categories (and corresponding codes) shown in Table 3: "landscape", "identity", "destruction", "spiritual", and "creation", each of which will be discussed in detail in Sect. 3. After these codes had been grouped as such we went back through each of the individual occurrences (e.g. the 61 segments of poetry that were categorised as landscape) to make sure that they did indeed belong in this category.

In this combination of code books to search for emergent categories, we found that some of our early individual coding had been done erroneously, e.g. in "Ice Child" by John Haines (1999), the following section was coded as identity by SI and destruction by AS; however, in the merger of our code books we decided that a more appropriate category was actually landscape, which as can be seen from Table 3 was not associated with either of these codes:

we find your interrupted life, placed here among the trilobites and shells, so late unearthed.

Following this categorisation, each of the five categories shown in Table 3 were further examined for any theme(s) that expressed underlying meaning in relation to the RQ, the results of which are presented in Sect. 3.7.

\subsection{Determination of trustworthiness}

At each stage of the qualitative content analysis that was adopted in this study, the individual codes and categories were re-examined in order to confirm that they accurately captured the poetry in relation to the RQ. Each of us carried out this coding independently, until there were no further codes or categories found to be emerging from the data, i.e. until descriptive saturation had been reached (Lambert and Lambert, 2012). Triangulation as a validation strategy (Flick, 2004) was achieved by using data drawn from different times and places (the poems) and conducting an analysis using two different investigators (the authors of this study). A combination of systematic sampling, triangulation and constant comparison, and proper audit and documentation (see Sect. 2.2 and 2.4) was used to ensure both the reliability (i.e. the consistency with which this analysis would produce the same results if repeated) and the validity (i.e. the accuracy or correctness of the findings) of this approach (Leung, 2015). Given that the analysis of the poetry as described here represents a somewhat subjective approach, the reliability of the findings might be called into question. However, as outlined by Morse et al. (2002), our methodological coherence, sampling strategy, and saturation of emergent codes ensures the reliability and trustworthiness of our approach in this qualitative analysis.

\section{Results and discussion}

As can be seen from Table 3, five major categories emerged from the thematic coding of the poems used in this study. We will now discuss each of these emergent categories, how they relate to the RQ (what does poetry written about volcanoes 
Table 2. The codes that emerged from an individual content analysis of the 34 poems, arranged according to the number of times they occurred (AS: Arianna Soldati; SI: Sam Illingworth).

\begin{tabular}{|c|c|c|c|}
\hline Code & Coder & Description & Occurrences* \\
\hline Landscape & AS & Simple description of volcanoes as part of the environment & 30 \\
\hline Human & AS & Referring to fellow human beings & 28 \\
\hline Destruction & AS & Associated with destruction & 24 \\
\hline Spiritual & AS & Evoking a spiritual connection or being & 23 \\
\hline Destruction & SI & Something that brings/is associated with destruction & 15 \\
\hline Creation & SI & Associated with new life and fostering life & 13 \\
\hline Plants & AS & Reference to plants/flowers & 13 \\
\hline Spiritual & SI & Associated with spiritual/religious feelings and/or presence & 12 \\
\hline History & AS & Bringing a historical perspective & 12 \\
\hline Death & AS & Associated with death & 12 \\
\hline Animals & AS & Reference to animals & 11 \\
\hline Identity & SI & Associated with a sense of identity for a person/people & 8 \\
\hline Fear & SI & Something to be feared/afraid of & 8 \\
\hline Cohabiting & SI & Living alongside the volcano (both positive and negative consequences) & 8 \\
\hline Natural beauty & SI & Described as something beautiful and/or awesome. & 7 \\
\hline Setting & SI & The volcano is a neutral setting for the poem & 6 \\
\hline Universe & AS & Reference to stars/planets & 5 \\
\hline Force/power & AS & Evoking the strength of the volcano & 5 \\
\hline Childhood & AS & Reminiscing about childhood & 4 \\
\hline Peace & AS & Relating to peace/absence of war & 3 \\
\hline Positive metaphor & SI & The volcano is used as a positive metaphor/simile & 2 \\
\hline Creation & AS & Evoking the creation of land or life & 2 \\
\hline Rocks/minerals & AS & Reference to the rock/mineral element of landscape & 2 \\
\hline Wish & AS & Expressing a desire, wish & 2 \\
\hline Time & AS & Encompassing the passage of time & 2 \\
\hline Quiet & AS & Related to a feeling of stillness, quiet & 2 \\
\hline Pain & AS & Related to physical pain & 1 \\
\hline Fear & AS & Related to a feeling of fear & 1 \\
\hline
\end{tabular}

* The number of occurrences is not limited to one per poem.

Table 3. The categories that emerged from the coding process, alongside their corresponding codes, and arranged according to the number of times they occurred (AS: Arianna Soldati; SI: Sam Illingworth).

\begin{tabular}{|c|c|c|}
\hline Category & Corresponding codes (author) & Occurrences $^{\mathrm{a}}$ \\
\hline Landscape & $\begin{array}{l}\text { Landscape (AS); natural beauty (SI); universe (AS); } \\
\text { rocks/minerals (AS); force/power (AS); } \\
\text { Animals (AS); plants (AS); setting (SI) }\end{array}$ & 61 \\
\hline Identity & $\begin{array}{l}\text { History (AS); heritage (AS); humans (AS); } \\
\text { identity (SI); childhood (AS); positive metaphor (SI); } \\
\text { time (AS) }\end{array}$ & 49 \\
\hline Destruction & $\begin{array}{l}\text { Death (AS); pain (AS); destruction (S); destruction } \\
\text { (AS); fear (SI); cohabiting }{ }^{\text {b }} \text { (SI); fear (AS) }\end{array}$ & 36 \\
\hline Spiritual & Spiritual (AS); spiritual (SI) & 25 \\
\hline Creation & $\begin{array}{l}\text { Creation (SI); creation (AS); wish (AS); cohabiting }{ }^{b} \\
\text { (S); peace (AS); quiet (AS) }\end{array}$ & 8 \\
\hline
\end{tabular}

a The number of occurrences is not limited to one per poem. ${ }^{b}$ This code originally had both positive and negative connotations. 
reveal about the relationship between volcanoes and the societies and times represented by poets who wrote about them?), and how these findings compare to other research that has been conducted into the changing perceptions of volcanoes (Sect. 3.1-3.5).

Following a discussion of these categories we present a quantitative analysis of the poems in terms of how the frequency of these emergent categories have changed over time (Sect. 3.5), followed by a presentation of the overall theme that emerged from conducting this analysis, and how this relates to the RQ (Sect. 3.6).

\subsection{Landscape}

Landscape is the most recurrent of the five emergent categories, being present in every poem that was analysed, regardless of when it was written. Here volcanoes serve primarily as a backdrop; they are part of the environment where the poem is set, typically a prominent feature that dominates the landscape. For example, in "Hunched Back Volcano" by Genevieve Taggard (1914), the poet paints a particularly vivid image of an active volcano, anthropomorphised as having a passionate (erupting) mouth (crater), set against a backdrop of stars:

Red is the mouth of Pele, passionate

Against the fires of the kindling stars:

Fire to fire moves: the heavens wait

By contrast, in "Mount Broadshield" by Jónas Hallgrímsson (1841) the volcano is now quiet and peaceful - an image highlighted by the presence of snow - though it still dominates the landscape with its (regal) presence:

Queen of all our country's mountains, crowned with snow sublime and pure! Once you poured from fiery fountains floods of lava down the moor.

In "Flowers from the Volcano" by Claribel Alegría (2013), the volcanic crater, presumably at least temporarily inactive, becomes part of the human landscape, representing the place where the flower growers of the poem now live:

Farther up, in the crater

within the crater's walls

live peasant families

who cultivate flowers

their children can sell.

Even in its absence, the volcano can still dominate the landscape. For example, in "Road Trip" by Vijay Seshadri (2016), it is not the volcano itself which provides the poem's setting, but rather the beaches that came from its erosion, with their black sand and tide pools excavated in its obsidian lava:
Tomorrow or the day after or the day after that, on the volcano beaches fringed with black sand and heaped with tangled beds of kelp,

by the obsidian tide pools that cradle the ribbed

limpet

and the rockbound star,

These poems also capture the effect that volcanoes have in changing the landscape, such as in "Peace" by David Herbert Lawrence (1929), which provides a description of an effusive eruption - firstly, as it occurs:

Brilliant, intolerable lava

Brilliant as a powerful burning-glass

Walking like a royal snake down

the mountain towards the sea.

And then, after the eruption has ceased:

Peace congealed in black lava on the doorstep.

Within, white-hot lava, never at peace

Till it burst forth blinding, withering the earth;

To set again into rock

Grey-black rock.

These descriptions of the changing landscape also highlight how the language that is used by poets in their descriptions can both reinforce and counteract scientific terminology and understanding. The likening of lava to glass is scientifically accurate, as both lava and glass are examples of a silicate melt. In contrast to this, the use of colour in this passage, whilst evocative, is not actually grounded in reality: lava does indeed turn into black or grey-black rock as it cools down, but is never white-hot. The colour choice may have been dictated by a contrast (black vs. white) or by the idea, pushed further than it actually occurs in reality, that the hotter something gets the closer it gets to white (with lava typically stopping at red-orange), and the idea of hot, molten lava still persisting within a cooled, solid outer crust does in fact accurately reflect the inward cooling process of lava flows. This is of course not to say that poems should ensure scientific accuracy at the cost of their aesthetics; we draw attention to these scientific inaccuracies only to highlight that we are not interested in how accurately these poems capture volcanic behaviour, but rather what the poetry can tell us about the relationship between volcanoes and the societies and times represented by poets who wrote about them. This use of poetry mirrors that which Aristotle observed in Poetics, i.e. that whilst history deals with specific events, poetry deals with general truths (Yanal, 1982).

The fact that volcanoes feature so prominently as a setting in these poems highlights that the poets perceived very clearly how volcanoes could relate to their societies and times. Similarly, the language used in the poetry acts to position volcanoes as an awesome part of our shared landscape, perhaps explaining in part why humans were first drawn to them before they became valued for more tangible goods 
such as precious metals and stones (Fisher et al., 1998), as well as soil fertility.

\subsection{Identity}

Volcanoes are often used to represent or highlight part of the poet's identity. They are present in their childhood memories, as well as in family history or cultural heritage. Identity is the second most recurrent category (after landscape), missing from only two of the analysed decades: the 1860s and 1880s. This ubiquity is extremely revealing of the profound tie between humans and volcanoes; here the volcanoes are not merely passive elements of the landscape, but rather active agents. Even when they are standing still, their presence is so impactful as to be defining for the poet, as evidenced in "Punctuation Marks" by Phillip Nanton (1992), set on the author's native island of Saint Vincent (Saint Vincent and the Grenadines), whose landscape is metaphorically dominated by the active volcano La Soufrière:

Come nearer, focus on one dot of an island

I was born there, on the rim of a volcano

on the edge of a large full stop

where the sand is black

where the hills turn a gun-barrel blue

where the sea perpetually dashes at the shoreline

trying to reclaim it all.

Similarly, in "Flowers from the Volcano" by Claribel Alegría (2013), the poet's home country of El Salvador is remembered nostalgically, its personal resonance defined by the situation of its volcanoes:

Fourteen volcanos rise in my remembered country

in my mythical country.

In this poem, the volcanoes represent not only the literal volcanoes in that region, but also the eruption of violence brought about by the civil wars of the 1970s and 1980s across El Salvador, Nicaragua, and Guatemala, and how they too came to form a part of the poet's life and identity.

This personalisation of the volcano is continued in "Sonnet 5" by Pablo Neruda (1959), for whom volcanoes become the distinctive feature of his native Chile, elevated to the same rank as the love/lover which the poet found there:

and on through the streets like a man wounded, until I understood, Love: I had found my place, a land of kisses and volcanoes.

In many of these instances of identity, the volcano takes centre stage in a formative childhood memory, such as in "What For" by Garrett Hongo (1982), where the poet expresses the extent to which his childhood identity was itself defined by the presence of volcanoes:
I lived for the red volcano dirt staining my toes, the salt residue of surf and sea wind in my hair, the arc of a flat stone skipping in the hollow trough of a wave.

In contrast to this, "Axis" by Ray Gonzalez (2015) captures the way in which a particular volcano is a matter of family history, a mythical entity that the poet himself did not experience personally, but which is nonetheless present in the defining stories of his heritage:

The volcano in my grandmother's Mexican village smothered the town, though the girl escaped because

the axis of revolution sent her family into exile,

Here this identity is not necessarily a positive one: the forced exile of the poet's grandmother is remembered as an environmental revolution which they were powerless to avoid, but which became a defining aspect of both the grandmother and her grandson's assumed identity.

Identity is a nuanced concept and has both positive and negative connotations associated with it. However, what is evident from these poems is that these associations are typically not purely adverse, and even when they are they form important societal ties that have come to define both past and current generations. Although the destructive impacts of volcanoes are well documented and recognised, many of the possible societal and cultural benefits are not always fully considered (Kelman and Mather, 2008), and the emergence of identity as a key category across the majority of the analysed poems serves to further highlight this disparity.

\subsection{Destruction}

This category considers those poems that make reference in some part to the destructive power of volcanoes, in relation to humankind. Poems that were categorised as such include those that make reference to physical damage of societal assets or destruction to human beings, such as is evident from this extract from "Blankets of Blood" by Arthur Rimbaud (1872):

Oh my friends! - My heart knows its own brothers! Dark strangers, what if we were to leave? So leave!

Leave!

O misfortune! How the earth melts upon us,

How I shake as it melts on me and you,

These poems also consider those that make reference to physical damage or destruction to property or land that is owned and/or cherished by humans, such as in this passage from "Peace" by David Herbert Lawrence (1929):

Forests, cities, bridges

Gone again in the bright trail of lava. 
Naxos thousands of feet below the olive-roots, And now the olive leaves thousands of feet below the lava fire.

This category also includes those poems that highlight the mental anguish of people caused by the negative effects of volcanoes, either directly through their eruptions or indirectly through the oppressive nature of living within close proximity to them, as can be seen in this extract from "Negotiations with a Volcano" by Naomi Shihab Nye (1995):

We need dreams the shape of lakes, with mornings in them thick as fish. Shade us while we cast and hook but nothing else, nothing else.

The permeating sense of fear that is evident from this extract acts as a powerful testament to the severe mental anguish that experiencing a volcanic eruption and/or living near an active volcano can have on local residents, capturing these negative mental health effects in a manner that does not diminish them in comparison to more tangible examples of volcanic destruction. Research into the mental health impacts following volcanic eruptions has shown that nearby residents are at an increased risk of experiencing symptoms of post-traumatic stress disorder (Gissurardóttir et al., 2019) and mental stress due to the loss (or threat of loss) of property (Horwell et al., 2015). Indeed, such research has also highlighted the importance of implementing psychosocial interventions with volunteers, both during and after a volcanic eruption, in order to alleviate severe mental health risks (Espinoza et al., 2019). By highlighting the mental distress that volcanoes can cause to humans, these poems serve to highlight why this should not be neglected when considering the potential impacts of volcanic activity.

Finally, this category also considers those poems in which volcanoes are responsible for the fatality of human beings, as can be seen in these lines from "Flowers from the Volcano" by Claribel Alegría (2013):

Eternal Chacmol collects blood, the gray orphans

the volcano spitting bright lava

and the dead guerrillero

and the thousand betrayed faces,

the children who are watching

so they can tell of it.

Here "Chacmol" likely refers to a distinctive form of Mesoamerican sculpture associated with sacrifice, and in this poem, the poet asks us to reflect on the role of the volcanoes in shaping the landscape of Central America. Through death, several of these poems invite us to consider how such sacrifices can result in new creation (see Sect. 3.5), but they also serve as a reminder to the reader of the vast power that these volcanoes possess, encouraging us humans to both respect and, at times, fear their presence.
Given the severe destruction that volcanoes can wreak, as highlighted by this emergent category, these poems might suggest that communities would not choose to live in such environments of their own volition. However, when such destructive incidents occur in the poetry, they rarely appear in isolation, and instead tend to appear alongside other categories which represent potential benefits, not least identity (Sect. 3.2) and creation (Sect. 3.5). This contrast of categories implies that in many instances the poets were intending to capture a mutuality of both potential hazards and benefits. This interpretation further supports the findings of other studies which have highlighted that many communities choose to expose themselves to the negative consequences of volcanic hazards, so that they might enjoy the benefits and opportunities that arise within the human-volcano system (see for example Bachri et al., 2015; Stoffle et al., 2015).

\subsection{Spiritual}

As can be seen from Tables 2 and 3, this category emerged from a single code, which we both independently labelled as such. This category represents those poems that were considered to make reference to aspects of volcanoes that were of spiritual significance. Some of the poems that were coded in this category make a specific mention of religious figures, such as these references to Christ in "Etna" by Emily Pfeiffer (1889):

Martyr of mountains, shall I say, the Christ,

Bearing earth's sorrows, for its trespass made

Sin, that her sons may reap the fair increase

Of smiling fields? The offering hath sufficed:

And also those in 'St Telemachus' by Alfred Tennyson (1892):

In the great name of Him who died for men,

Christ Jesus!" For one moment afterward

A silence follow'd as of death, and then

A hiss as from a wilderness of snakes,

Then one deep roar as of a breaking sea,

And then a shower of stones that stoned him dead,

And then once more a silence as of death.

Given the selection of English-language poems for this study, there is a strong weighting towards poems that make reference to biblical figures from Christianity, although other religious figures, such as the Buddha and several Mesoamerican deities, also feature, especially in those poems which were originally written in another language, and yet for which an author-sanctioned translation exists (see Sect. 2.2). For example, in "A tale for Puuooo" by Taeko Jane Takahashi (2002), we hear how

Pele the goddess pierced and thrusted, spilling lava into Royal Gardens subdivision. 
Here, Pele is the goddess of volcanoes and fire in the Hawaiian religion, where she is also considered to be the creator of the Hawaiian Islands. In some instances, the volcano itself is considered to be the chief religious figure or deity, such as in these lines from "Ice Child" by John Haines (1999), in which the volcano is explicitly referred to as a now dormant god:

Under the weight of this mountain once a god, now only restless stone, we find your interrupted life,

placed here among the trilobites

and shells, so late unearthed.

Or in "Burning Island" by Gary Snider (1970), in which the volcano is given the status of a spiritual creator and protector:

Volcano belly Keeper who lifted this island

for our own beaded bodies adornment

and sprinkles us all with his laugh -

At times this spirituality manifests itself with the poet (or their protagonist) appealing to the volcano for either forgiveness or clemency, such as in "Negotiations with a Volcano" by Naomi Shihab Nye (1995), where the author pleads for mercy with the volcano as they might do with another deity or spiritual figure:

Forgive any anger we feel toward the earth, when the rains do not come, or they come too much,

and swallow our corn.

It is not easy to be this small and live in your shadow.

These lines also demonstrate how this associated spirituality serves to create an "otherness", i.e. that volcanoes and humans might occupy the same landscape but they are vastly different entities in terms of both temporal and spatial scales. The separation that is imposed by this emergent spirituality also highlights potential difficulties for cohabiting. There is at times a perceived unidirectional flow of power that makes establishing a truly symbiotic relationship seem improbable, as can be seen in the following lines from "Ice Child":

Was it God - the sun-god of the Incas,

the imperial god of the Spaniards?

Or only the priests of that god,

self-elected - voice of the volcano

that speaks once in a hundred years.

The interpretations of volcanic eruptions have been shown to be interconnected with the understanding of tradition by different religions and religious figures (see for example Gaillard and Texier, 2010). The poems that feature in this category further demonstrate that there is clearly a spiritual connection between volcanoes and humans, whilst also serving to highlight the spiritual reverence in which volcanoes are held, and the distance that this can introduce. By considering the spirituality of volcanoes, these poems also ask us to contemplate the persistence of the spiritual life system within a particular territory, aligning with previous research which has shown how, when humans push these boundaries in order to exploit them, the system can become disrupted (Vitale, 2017).

\subsection{Creation}

The final category to emerge from this analysis is one of creation. Poems that feature in this category demonstrate how volcanoes can act as a creative (as opposed to, or in addition to, being a destructive) force. For example, "Darkness" by George Byron (1816) unknowingly explores the aftermath and potential consequences of the 1815 eruption of Mt Tambora, Sumbawa, Indonesia, an event whose subsequent volcanic winter resulted in the infamous "year without a summer" (Stommel and Stommel, 1979), as it would have been later discovered. Yet, despite the overall negative connotations of this poem, Byron still recognises that prior to this eruption living alongside volcanoes was a positive experience, a source of happiness even:

Happy were those who dwelt within the eye Of the volcanos, and their mountain-torch:

Another poem that demonstrates the creative potential of the volcano is 'Burning Island' by Gary Snider (1970), in which the poet asks us to consider the fertile soils that volcanoes provide, enabling a peaceful and profitable cohabitation:

As we hoe the field

let sweet potato grow.

And as sit us all down when we may

To consider the Dharma

bring with a flower and a glimmer.

Let us all sleep in peace together.

Many residents who live near volcanoes view eruptions as agents of change, often change for the better (Dove, 2008), which can in turn influence the extent to which they perceive the hazard and risk of living of living near volcanoes. "Burning Island" highlights the potential benefits of living in volcanic regions, where the rich volcanic soils can support highly productive agriculture (Rampengan et al., 2016). However, it also draws attention to the fact that the benefits of this relationship would appear to be unidirectional volcanoes do not benefit from cohabiting the landscape with humans.

Continuing with notions of cohabiting, this category features those poems that demonstrate how such a relationship can be peaceful. For example, in "Peace" by David Herbert Lawrence (1929) the concept of placatory cohabitation is explored in the very first lines: 
Table 4. Poem connotation and categories by decade. In this table each decade was considered to have an associated connotation if at least one poem written in this decade was considered to be either neutral, positive, negative, or both. Similarly, a particular decade was assumed to be associated with an emergent category if at least one of the poems that were written in that decade was categorised as such.

\begin{tabular}{|c|c|c|c|c|c|c|c|c|c|}
\hline \multirow[b]{2}{*}{ Decade } & \multicolumn{4}{|c|}{ Connotation } & \multicolumn{5}{|c|}{ Categories } \\
\hline & Neutral & Both & Positive & Negative & Landscape & Identity & Creation & Destruction & Identity \\
\hline 1800 & $\mathrm{X}$ & & & & $\mathrm{X}$ & $\mathrm{X}$ & & $\mathrm{X}$ & \\
\hline 1810 & & & & $\mathrm{X}$ & $\mathrm{X}$ & $\mathrm{X}$ & $\mathrm{X}$ & $\mathrm{X}$ & \\
\hline 1820 & $\mathrm{X}$ & & & & $\mathrm{X}$ & $\mathrm{X}$ & & & $X$ \\
\hline 1830 & $\mathrm{X}$ & & & & $\mathrm{X}$ & $\mathrm{X}$ & & & $\mathrm{X}$ \\
\hline 1840 & & $\mathrm{X}$ & & & $\mathrm{X}$ & $\mathrm{X}$ & $\mathrm{X}$ & $\mathrm{X}$ & $\mathrm{X}$ \\
\hline 1850 & & & & $\mathrm{X}$ & $\mathrm{X}$ & $\mathrm{X}$ & & & $\mathrm{X}$ \\
\hline 1860 & & & & $\mathrm{X}$ & $\mathrm{X}$ & & & $\mathrm{X}$ & \\
\hline 1870 & & & & $\mathrm{X}$ & $\mathrm{X}$ & & & $\mathrm{X}$ & \\
\hline 1880 & & $\mathrm{X}$ & & & $\mathrm{X}$ & & & $\mathrm{X}$ & $\mathrm{X}$ \\
\hline 1890 & & & & $\mathrm{X}$ & $\mathrm{X}$ & $X$ & & $\mathrm{X}$ & $\mathrm{X}$ \\
\hline 1900 & & & $\mathrm{X}$ & & $\mathrm{X}$ & $\mathrm{X}$ & & & \\
\hline 1910 & & & $\mathrm{X}$ & & $\mathrm{X}$ & $\mathrm{X}$ & & $\mathrm{X}$ & \\
\hline 1920 & & $X$ & & $\mathrm{X}$ & $\mathrm{X}$ & $\mathrm{X}$ & $\mathrm{X}$ & $\mathrm{X}$ & \\
\hline 1930 & & & & $\mathrm{X}$ & $\mathrm{X}$ & $\mathrm{X}$ & & $\mathrm{X}$ & \\
\hline 1940 & & & & & & & & & \\
\hline 1950 & & $\mathrm{X}$ & & & $\mathrm{X}$ & $\mathrm{X}$ & & & \\
\hline 1960 & & & & & & & & & \\
\hline 1970 & $\mathrm{X}$ & & $\mathrm{X}$ & & $\mathrm{X}$ & $X$ & $\mathrm{X}$ & & $\mathrm{X}$ \\
\hline 1980 & & & $\mathrm{X}$ & $\mathrm{X}$ & $\mathrm{X}$ & $\mathrm{X}$ & $\mathrm{X}$ & $\mathrm{X}$ & $\mathrm{X}$ \\
\hline 1990 & & & $\mathrm{X}$ & & $\mathrm{X}$ & $\mathrm{X}$ & $\mathrm{X}$ & $\mathrm{X}$ & $\mathrm{X}$ \\
\hline 2000 & & & & $\mathrm{X}$ & $\mathrm{X}$ & $\mathrm{X}$ & & $\mathrm{X}$ & $\mathrm{X}$ \\
\hline 2010 & $\mathrm{X}$ & & $\mathrm{X}$ & $\mathrm{X}$ & $\mathrm{X}$ & $\mathrm{X}$ & & & $\mathrm{X}$ \\
\hline
\end{tabular}

PEACE is written on the doorstep

In lava.

Here the potentially destructive lava gets all the way to the house, yet stops on the doorstep, respectful of the human space. However, even here the potential dangers of this cohabitation are clearly apparent: is this message from the volcano a genuine offering of peace, or a warning shot across the bow - a reminder to humans of their position in the hierarchical relationship that emerges through a consideration of the spiritual (Sect. 2.4)? "Negotiations with a Volcano" by Naomi Shihab Nye (1995) further explores the fragile nature of this cohabitation, explicitly wishing for the volcano to remain dormant, and offering to be peaceful themselves if this wish is granted:

We would be happy if you slept forever.

We will tend the slopes we plant, singing the songs our grandfathers taught us before we inherited their fear.

We will try not to argue among ourselves.

In considering the potential for a creative and peaceful cohabitation of the landscape, this category demonstrates how such a relationship is conditional, and is reliant on the volcanoes to "behave" in a certain manner towards (or with respect to) humans.

\subsection{Quantitative analysis}

After performing this qualitative content analysis, we quantitatively analysed how both the connotation of volcanoes (neutral, positive, negative, positive and negative) as well as the frequency of the five emergent categories evolved through time in our dataset. In order to do so, we aggregated our dataset by decade and normalised the identified connotations and categories to the number of poems in which they were represented (Table 4). Furthermore, we considered the major eruptions which occurred in the Northern Hemisphere (where the majority of the poets in this study lived) across the considered time frame (Table 5) and correlated these with the connotations and categories of the dataset. Due to the limited sample size $(n=34)$, this quantitative analysis cannot be considered statistically significant. The purpose of this quantitative analysis was not to apply a statistical interpretation of the volcano-human interactions of the analysed poetry; rather it was read alongside the qualitative analysis in support of the emergent theme (Sect. 3.7) that arose from a consideration of these poems.

As can be seen from Fig. 1, poems in which volcanoes have either a neutral or both a positive and negative connotation, and therefore do not express a partial value judgement, can be found consistently throughout the time span considered (i.e. from the 1800 s to the 2010 s). The same can also be 
Table 5. Some of the major eruptions from the 1800s to the present day. These are defined as those eruptions having had either a Volcanic Explosivity Index (VEI) greater than three, and having occurred in the Northern Hemisphere, where the majority of the authors of the considered poems lived, or having had a global impact and resonance. Data taken from the Global Volcanism Program (Venzke, 2013).

\begin{tabular}{lr}
\hline Volcano & Eruption year \\
\hline Tambora & 1815 \\
Krakatoa & 1883 \\
La Soufrière, Pelée, Santa Maria & 1902 \\
Novarupta & 1912 \\
Paricutin & $1943-1954$ \\
Vesuvius & 1944 \\
Hekla & $1947-1948$ \\
Surtsey & 1963 \\
St Helens & 1980 \\
El Chichon & 1982 \\
Redoubt & 1989 \\
Pinatubo & 1991 \\
Eyjafjallajökull & 2010 \\
\hline
\end{tabular}

said for poems where volcanoes are depicted with an overall negative connotation. In contrast, a positive representation of volcanoes only emerges in the 1900s, and does not become frequent until the 1970s.

Plotting major eruptions alongside the associated connotations of the selected poems (Fig. 1) does not reveal any obvious correlation. This can be attributed to the fact that the vast majority of the analysed poems do not focus on specific volcanic eruptions, but rather that they consider humanvolcano interactions more generally. One notable exception is the poem "Darkness" by George Byron (1816), which as discussed in Sect. 3.5 is grounded in the eruption of Mount Tambora in 1815, and the subsequent "year without summer". During this eruption, volcanic ash was injected high into the stratosphere, where it circled the globe and persisted for a considerable time, visibly filtered the sunlight, and caused a negative thermal anomaly of at least $0.5^{\circ} \mathrm{C}$ in the Northern Hemisphere, as well as a famine that ultimately killed over 70000 people. This event inspired artists in all fields (e.g. Turner's famous sunset paintings, and Mary Shelley's Frankenstein), with Byron's poem also bearing witness to this event:

I had a dream, which was not all a dream.

The bright sun was extinguish'd, and the stars

Did wander darkling in the eternal space,

Rayless, and pathless, and the icy earth

Swung blind and blackening in the moonless air;

Morn came and went - and came, and brought no day,

At the categories scale (Fig. 2), we see that the volcanohuman interactions in relation to the landscape occur in all represented decades (as discussed in Sect. 2.2 the 1940s and 1960s are not represented in this analysis). The notions of identity that are associated with these interactions are almost as ubiquitous, with the only exceptions being the 1860 s and 1880s.

As can be seen from Fig. 2, the destruction in the volcanohuman interactions of the selected poetry is represented more frequently across the considered time period than the creation of such interactions. There is also somewhat of a correlation between destruction and each of the major volcanic eruptions that happened in this period, with the 1900s being the only decade which featured a major volcanic eruption in the Northern Hemisphere (Table 5) and which did not feature a poem that considered the destructive nature of volcanohuman interactions (again noting that the 1940s and 1960s are not represented in this analysis). This would indicate that even if poets were not writing about specific volcanic events, their attitudes might have been affected by them (and the social and economic impacts that these large volcanic events resulted in), leading to poems that more readily considered the destructive rather than creative nature of such interactions.

The spiritual category occurs across the considered time period, with a notable gap in the first half of the twentieth century. This might in part be explained by the tensions between poetry and religion that had manifested themselves throughout the Victorian age (because of the constraints in the selection of the poetry discussed in Sect. 2.2, the majority of the poems from this era came from either British or American writers), with religion becoming increasingly personal and secular as society became more democratic (Fraser, 1986). Similarly, the re-appearance of this category in later poems corresponds to the emergence of a new Romantic movement that began in the 1960s, in which people (and poets) began identifying themselves as "spiritual but not religious" (Thomas, 2006), which could explain the reemergence of spirituality in the poetry of this period.

\subsection{An emergent theme}

In considering the five categories identified in this analysis of the poetry, a clear theme emerges with respect to the RQ (what does poetry written about volcanoes reveal about the relationship between volcanoes and the societies and times represented by poets who wrote about them?): that there is a strong sense of identity between humans and volcanoes.

An analysis of these poems has revealed that humans and volcanoes occupy the same landscape, and that whilst there is a certain reverence associated with their destruction, there are also many positives associated with living alongside them. Surprisingly, however, these positives are mainly linked to notions of identity (e.g. family histories and cultural heritages) rather than the physical benefits of creation (e.g. fertile soils). These poems also highlight that this is a unidirectional relationship, in part because of the distancing brought about by the associated spirituality or otherness of the volca- 

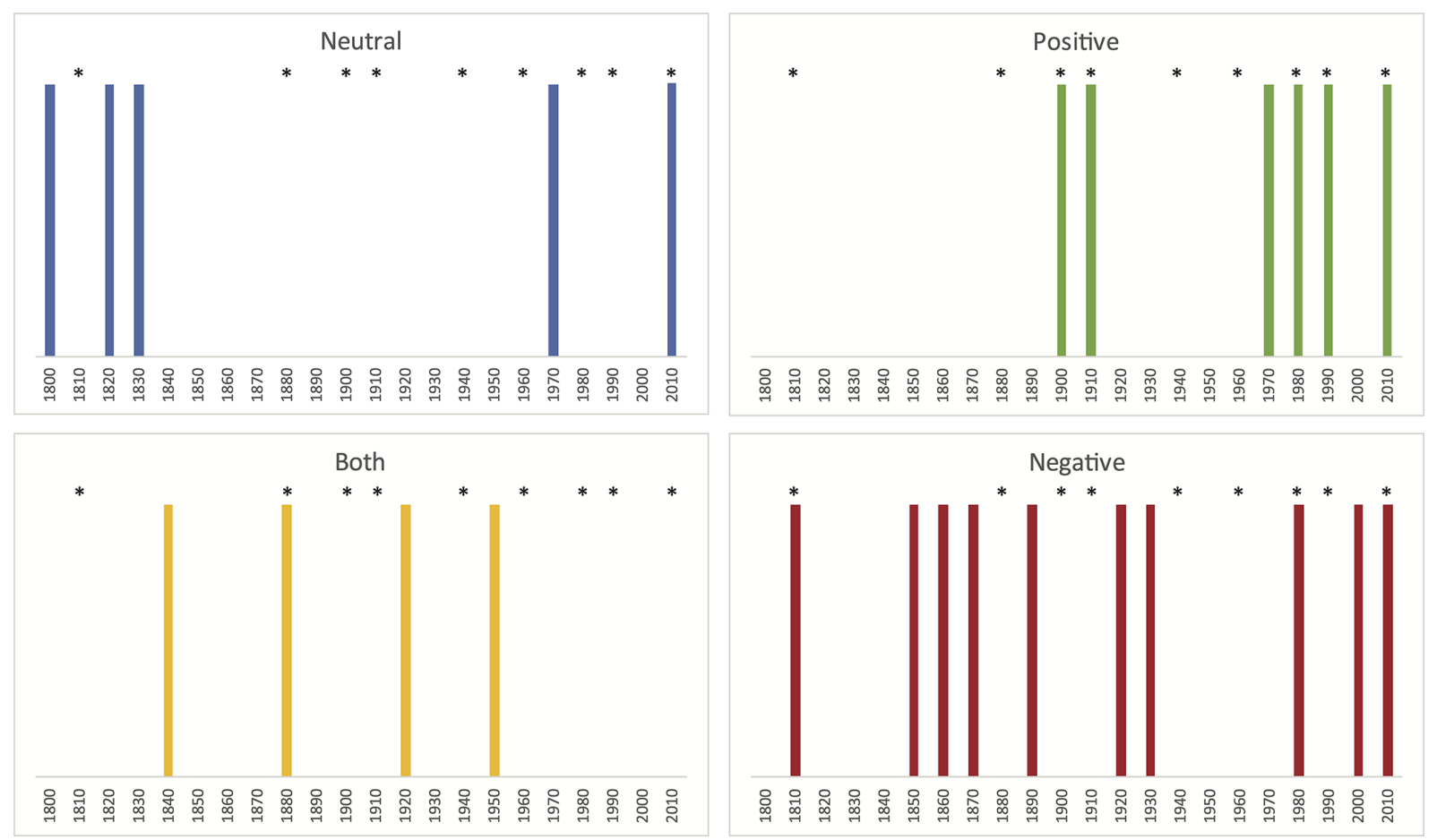

Figure 1. Connotations (neutral, positive, negative, or both) of the considered poems, arranged chronologically and aggregated by decade. Asterisks indicate major eruptions (as shown in Table 5).

noes, with humans ultimately of neither benefit nor concern to the volcanoes that they write about. A different selection of poems, including work from indigenous communities who grant volcanoes a higher cultural stand (e.g. personification or divinisation), might yield a different perspective.

This emergent theme is further supported by the quantitative analysis discussed in Sect. 3.6, where over the time period considered there is a relative ubiquity of the theme of identity in the poems. Similarly, despite the major cultural and societal changes that have occurred over this time period, attitudes towards human-volcano interactions have not noticeably shifted in favour of one category or another; the volcanoes have remained ever present, suggesting that they are impervious to these changes and further highlighting their unidirectional relationship with the poets that wrote about them, and in turn the societies and times that they represent.

\section{Conclusions}

The purpose of this study was to investigate what poetry written about volcanoes reveals about the relationship between volcanoes and the societies and times represented by the poets who wrote about them. By conducting a qualitative content analysis of a selection of poems written from the 1800 s to the present day, a series of themes emerged that characterised this relationship. The volcanoes as landscape and identity were seen as dominant, with consideration also given to the destruction and spirituality associated with these human-volcano interactions, and to a lesser extent their potential for creation. The main theme to emerge, both from these categories and the poems themselves, is that there is a strong sense of identity associated with volcanoes by humans (e.g. in terms of family histories, cultural heritage), and that it is the humans (and not the volcanoes) that are affected by this relationship. A quantitative analysis of the frequency with which these categories occurred throughout the decades of this dataset supported the findings of this qualitative analysis, thereby further improving the validity and reliability of the main finding of this study, i.e. that the relationship between volcanoes and the societies and times of the poets who wrote about them is unidirectional and focused on identity.

The outcomes of this study support other research findings which have demonstrated that many communities are willing to accept the associated risks of living near volcanoes, including active ones, in order to experience the cultural and societal benefits (i.e. identity) that they afford (see for example Schmincke, 2004; Kelman and Mather, 2008). Furthermore, by asking us to consider the emergent unidirectional nature of this relationship, this study also challenges us to reconsider our interactions with volcanoes. Unlike many other elements of our natural environment that have a strong sense of cultural and social identity attached to them - for example, glaciers (Gagné et al., 2014), rivers (Macklin, 1999), and rainforests (Roosevelt, 2013) - volcanoes are unlikely to be affected by, for example, anthropogenic climate change. In- 

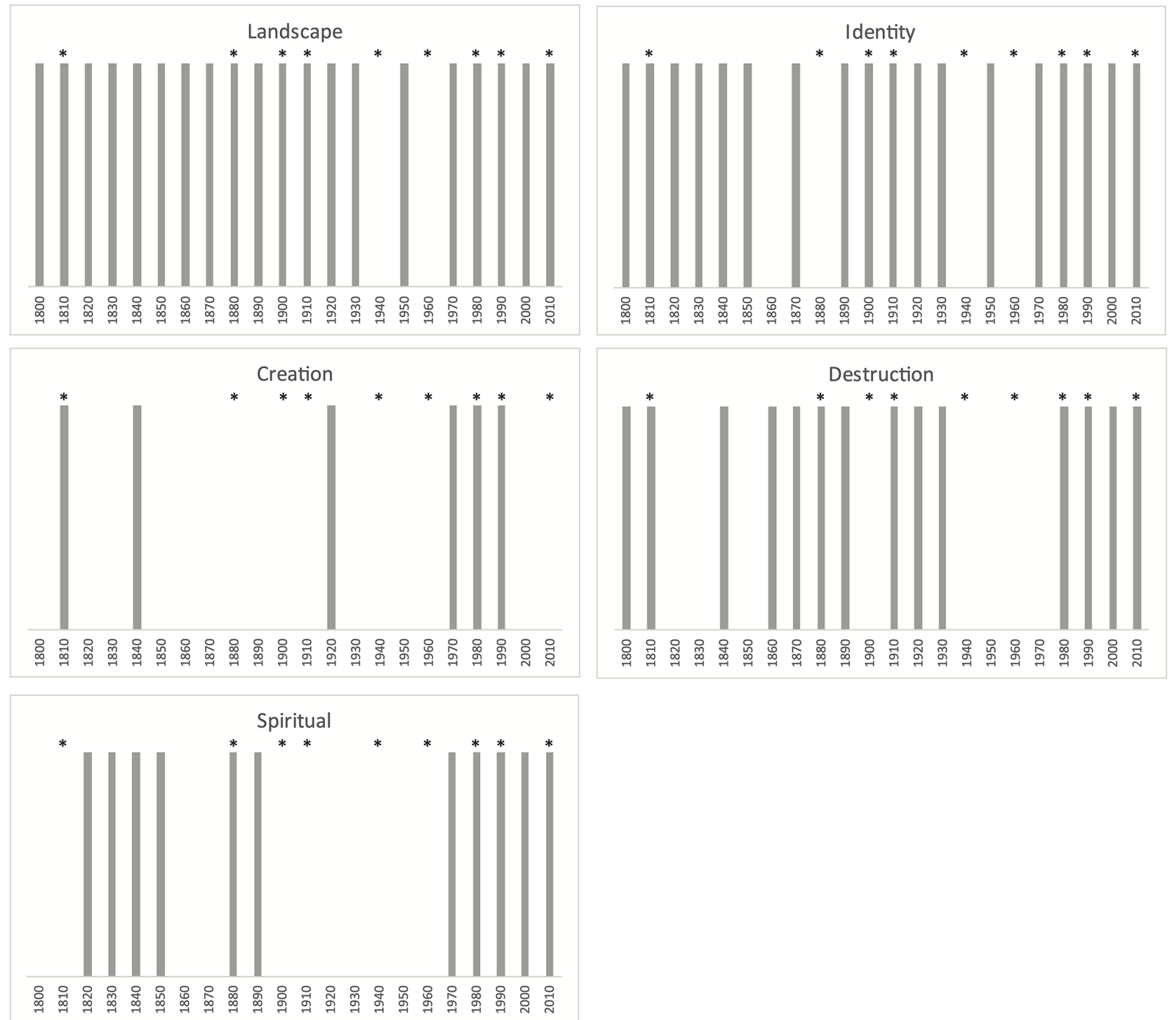

Figure 2. Emerging categories in the considered poems, arranged chronologically and aggregated by decade. Asterisks indicate major eruptions (as shown in Table 5).

deed, aside from humans, volcanism is itself a key driver in short-term climatic variations.

The main limitation for this study is that only Englishlanguage poems were considered. This means that there is likely a bias towards certain attitudes or behaviours, especially those that were found to emerge from the spirituality category. Future research could, and should, include poetry written in multiple languages to account for this limitation, as doing so would reveal a broader understanding of how poets interpret human-volcano interactions, especially for communities from the Southern Hemisphere. Additionally, the majority of poems considered were authored by male poets, due to the scarcity of poems about volcanoes written by female poets, especially for the nineteenth century. It is also worth noting that throughout the 220 years considered in this study, the cultural, social, and political backdrop of the poems has changed significantly. For example, colonialism has the potential of having significantly affected the representation of cultural elements in poetry. Whereas a detailed analysis of how these changes affected the content and tone of the poems is beyond the scope of this work, future studies focussing on this aspect would certainly be valuable. Finally, the limited size of the analysed dataset, i.e. 34 poems, advises caution when extrapolating the findings of this study to the poets' fellow human beings.

In addition to future studies considering a wider variety of languages and cultures, such work might also consider how different attitudes towards human-volcano interactions are captured by those poets who have physically encountered a volcano versus those who are relying on second-hand testimony. Furthermore, by outlining how poems can be used as a form of data to provide further insight into how human- 
volcano interactions are perceived, this study suggests that a similar approach might also be adopted for other geoscientific events or phenomena.

This study has demonstrated that poetry is a powerful medium through which to consider perceptions of our natural environment. Our methodology could become an integral part of a deeper analysis to develop communication strategies with communities living near active volcanoes. For example, it could provide more appropriate (i.e. locally sourced) language to engage the communities in conversation. It is in fact critical that local cultural and religious beliefs be taken into account when communicating volcanic hazard, as demonstrated by several social volcanology studies (Cashman and Cronin, 2008; Donovan, 2010; Lavigne et al., 2008; Paton et al., 2008). We encourage interested readers to get in contact with us for participation in the next stage of this research, in which we hope to broaden our analysis beyond the constraints of the English language.

Data availability. The poems that were selected for the analysis, along with their coded categories, are available through Soldati and Illingworth (2019; https://doi.org/10.17605/OSF.IO/2D5K6).

Author contributions. AS and SI worked together to conceive the design of this study, conduct the research and analysis, and write the paper.

Competing interests. Author Sam Illingworth is the chief executive editor of Geoscience Communication.

Acknowledgements. We would like to thank members of the Volcanology community who provided us with several poems to consider for our dataset. Furthermore, we would like to thank Alana Weir who provided useful comments to an earlier draft of this paper.

Review statement. This paper was edited by Mathew StillerReeve and reviewed by David Pyle, Christos S. Zerefos, and one anonymous referee.

\section{References}

Alexander, D. E.: The portrayal of disaster in Western fine art, Environmental Hazards, 15, 209-226, 2016.

Avvisati, G., Sessa, E. B., Colucci, O., Marfè, B., Marotta, E., Nave, R., Peluso, R., Ricci, T., and Tomasone, M.: Perception of risk for natural hazards in Campania Region (Southern Italy), Int. J. Disast. Risk Re., 40, 101164, https://doi.org/10.1016/j.ijdrr.2019.101164, 2019.

Bachri, S., Stötter, J., Monreal, M., and Sartohadi, J.: The calamity of eruptions, or an eruption of benefits? Mt.
Bromo human-volcano system a case study of an openrisk perception, Nat. Hazards Earth Syst. Sci., 15, 277-290, https://doi.org/10.5194/nhess-15-277-2015, 2015.

Brown, S. K., Auker, M., and Sparks, R.: Populations around Holocene volcanoes and development of a Population Exposure Index, Global Volcanic Hazards and Risk, Cambridge, UK, Cambridge University Press, 223-232, 2015.

Cashman, K. V. and Cronin, S. J.: Welcoming a monster to the world: Myths, oral tradition, and modern societal response to volcanic disasters, J. Volcanol. Geoth. Res., 176, 407-418, 2008.

Daly, N.: The volcanic disaster narrative: From pleasure garden to canvas, page, and stage, Victorian Stud., 53, 255-285, 2011.

Donovan, A., Oppenheimer, C., and Bravo, M.: Rationalising a volcanic crisis through literature: Montserratian verse and the descriptive reconstruction of an island, J. Volcanol. Geoth. Res., 203, 87-101, 2011.

Donovan, A., Ayala, I. A., Eiser, J., and Sparks, R.: Risk perception at a persistently active volcano: warnings and trust at Popocatépetl volcano in Mexico, 2012-2014, B. Volcanol., 80, 47, https://doi.org/10.1007/s00445-018-1218-0, 2018.

Donovan, K.: Doing social volcanology: exploring volcanic culture in Indonesia, Area, 42, 117-126, 2010.

Dove, M. R.: Perception of volcanic eruption as agent of change on Merapi volcano, Central Java, J. Volcanol. Geoth. Res., 172, 329-337, 2008.

Durant, A. J., Bonadonna, C., and Horwell, C. J.: Atmospheric and environmental impacts of volcanic particulates, Elements, 6, 235-240, 2010.

Esperanza, L. V., Luisa, M. M., Fabiola, F. E., and Adriana, P.: Volcanic Risk Exposure, Feelings of Insecurity, Stress, and Coping Strategies in México 1, J. Appl. Soc. Psychol., 38, 2885-2902, 2008.

Espinoza, A. E., Osorio-Parraguez, P., and Quiroga, E. P.: Preventing mental health risks in volunteers in disaster contexts: The case of the Villarrica Volcano eruption, Chile, Int. J. Disast. Risk Re., 34, 154-164, 2019.

Fisher, R. V., Heiken, G., and Hulen, J.: Volcanoes: crucibles of change, Princeton University Press, 1998.

Flick, U.: Triangulation in qualitative research, in: A companion to qualitative research, edited by: Flick, U., von Kardoff, E., and Steinke, I., 2004.

Fraser, H.: Beauty and Belief: Aesthetics and religion in Victorian literature, Cambridge, Cambridge University Press, https://doi.org/10.1017/CBO9780511896460, 1986.

Gagné, K., Rasmussen, M. B., and Orlove, B.: Glaciers and society: Attributions, perceptions, and valuations, WIRES Clim. Change, 5, 793-808, 2014.

Gaillard, J. C. and Texier, P.: Religions, natural hazards, and disasters: An introduction, Religion, 40, 81-84, https://doi.org/10.1016/j.religion.2009.12.001, 2010.

Gissurardóttir, Ó. S., Hlodversdóttir, H., Thordardóttir, E. B., Pétursdóttir, G., and Hauksdóttir, A.: Mental health effects following the eruption in Eyjafjallajökull volcano in Iceland: A population-based study, Scand. J. Public Healt., 47, 251-259, 2019.

Hamilton, J.: Volcano: nature and culture, Reaktion Books Ltd, London, 2013.

Horwell, C., Baxter, P., and Kamanyire, R.: Health impacts of volcanic eruptions, in: Global Volcanic Hazards and Risk, edited 
by: Loughlin, S. C., Sparks, R. S. J., Sparks, S., Brown, S. K., Jenkins, S. F., and Vye-Brown, C., Cambridge University Press, 289-294, 2015.

Hsieh, H.-F. and Shannon, S. E.: Three approaches to qualitative content analysis, Qual. Health Res., 15, 1277-1288, 2005.

Illingworth, S.: "This bookmark gauges the depths of the human": how poetry can help to personalise climate change, Geosci. Commun., 3, 35-47, https://doi.org/10.5194/gc-3-35-2020, 2020.

Illingworth, S. and Jack, K.: Rhyme and reason-using poetry to talk to underserved audiences about environmental change, Clim. Risk Manag., 19, 120-129, https://doi.org/10.1016/j.crm.2018.01.001, 2018.

Jack, K. and Illingworth, S.: "Saying it without saying it": using poetry as a way to talk about important issues in nursing practice, J. Res. Nurs., 22, 508-519, 2017.

Kelman, I. and Mather, T. A.: Living with volcanoes: the sustainable livelihoods approach for volcano-related opportunities, J. Volcanol. Geoth. Res., 172, 189-198, 2008.

Lambert, V. A. and Lambert, C. E.: Qualitative descriptive research: An acceptable design, Pacific Rim International Journal of Nursing Research, 16, 255-256, 2012.

Lavigne, F., De Coster, B., Juvin, N., Flohic, F., Gaillard, J.-C., Texier, P., Morin, J., and Sartohadi, J.: People's behaviour in the face of volcanic hazards: Perspectives from Javanese communities, Indonesia, J. Volcanol. Geoth. Res., 172, 273-287, 2008.

Leung, L.: Validity, reliability, and generalizability in qualitative research, Journal of family medicine and primary care, 4, 324-327, 2015.

Macklin, M. G.: Holocene river environments in prehistoric Britain: human interaction and impact, J. Quaternary Sci., 14, 521-530, 1999.

Morse, J. M., Barrett, M., Mayan, M., Olson, K., and Spiers, J.: Verification strategies for establishing reliability and validity in qualitative research, Int. J. Qual. Meth., 1, 13-22, 2002.

Nave, R., Ricci, T., and Pacilli, M. G.: Perception of risk for volcanic hazard in Indian Ocean: la Réunion Island case study, in: Active volcanoes of the Southwest Indian Ocean, Springer, 315326, 2016

Olson, M. S., Olson, D. W., and Doescher, R. L.: Marilynn S. Olson, Donald W. Olson, and Russell L. Doescher on the Blood-Red Sky of Munch's the Scream, Environ. Hist., 12, 131-135, 2007.

Paton, D.: Disaster risk reduction: Psychological perspectives on preparedness, Aust. J. Psychol., 71, 327-341, 2019.

Paton, D., Smith, L., and Johnston, D. M.: Volcanic hazards: risk perception and preparedness, New Zeal. J. Psychol., 29, 86-91, 2000.

Paton, D., Smith, L., Daly, M., and Johnston, D.: Risk perception and volcanic hazard mitigation: Individual and social perspectives, J. Volcanol. Geoth. Res., 172, 179-188, 2008

Poindexter, C. C.: Research as poetry: A couple experiences HIV, Qual. Inq., 8, 707-714, 2002.

Rampengan, M. M. F., Boedhihartono, A. K., Margules, C., Sayer, J., Law, L., Gaillard, J. C., Tien, O. T. N., and Linh, T. T. M.: Agroforestry on an Active Volcanic Small Island in I ndonesia: Prospering with Adversity, Geogr. Res., 54, 19-34, 2016.
Ribeiro, A. C.: Intending to repeat: A definition of poetry, J. Aesthet. Art Critic., 65, 189-201, 2007.

Roosevelt, A. C.: The Amazon and the Anthropocene: 13,000 years of human influence in a tropical rainforest, Anthropocene, 4, 6987, 2013.

Schmincke, H.-U.: Volcanism, Springer Science \& Business Media, 2004.

Schmitt, A. K., Danišík, M., Aydar, E., Şen, E., Ulusoy, İ., and Lovera, O. M.: Identifying the volcanic eruption depicted in a neolithic painting at Çatalhöyük, Central Anatolia, Turkey, PLoS One, 9, e84711, https://doi.org/10.1371/journal.pone.0084711, 2014.

Siebert, L., Simkin, T., and Kimberly, P.: Volcanoes of the World, University of California Press, 2011.

Sigurdsson, H.: The history of volcanology, Encyclopedia of Volcanoes, Elsevier, 15-37, 2000.

Sigurdsson, H.: Volcanoes in art, in: The encyclopedia of volcanoes, Elsevier, 1321-1343, 2015.

Sivard, S. M.: Upheaval and Transformation: The Volcano in American and European Art, 1765-1865, Columbia University, 2011.

Skinner, J.: A Distinctive Disaster Literature, Islanded identities: constructions of postcolonial cultural insularity, 139, 63, 2011.

Stoffle, R. W., Arnold, R., Frank, M., Cornelius, B., Miller, L., Charles, J., Kane, G., Ruuska, A. K., and Van Vlack, K.: Ethnology of Volcanoes: Quali-Signs and the Cultural Centrality of Self-Voiced Places, Engineering Mountain Landscapes: An Anthropology of Social Investment, 99-115, 2015.

Stommel, H. and Stommel, E.: The year without a summer, Sci. Am., 240, 176-187, 1979.

Sword-Daniels, V., Eriksen, C., Hudson-Doyle, E. E., Alaniz, R., Adler, C., Schenk, T., and Vallance, S.: Embodied uncertainty: living with complexity and natural hazards, J. Risk Res., 21, 290307, 2018.

Thomas, O. C.: Spiritual but not religious: The influence of the current romantic movement, Anglican Theological Review, 88, 397-415, 2006.

Vitale, R.: "Disaster is Nature Telling Us how to Live Resiliently": Indigenous disaster risk reduction, organizing, and spirituality in Tierradentro, Colombia, $62 \mathrm{pp}$. https://doi.org/10.21201/2017.0681, 2017.

Weier, K.: Empowering young children in art museums: Letting them take the lead, Contemporary Issues in Early Childhood, 5, 106-116, 2004.

Yanal, R. J.: Aristotle's Definition of Poetry, Nous, 499-525, 1982.

Zeilig, H.: Gaps and spaces: Representations of dementia in contemporary British poetry, Dementia, 13, 160-175, 2014.

Zerefos, C. S., Tetsis, P., Kazantzidis, A., Amiridis, V., Zerefos, S. C., Luterbacher, J., Eleftheratos, K., Gerasopoulos, E., Kazadzis, S., and Papayannis, A.: Further evidence of important environmental information content in red-to-green ratios as depicted in paintings by great masters, Atmos. Chem. Phys., 14, 2987-3015, https://doi.org/10.5194/acp-14-2987-2014, 2014. 